Cite this: J. Mater. Chem. A, 2014, 2 , 3725

Received 2nd December 2013 Accepted 19th December 2013

DOI: 10.1039/c3ta14982j

www.rsc.org/MaterialsA

\section{Creation of Brønsted acid sites on Sn-based solid catalysts for the conversion of biomass $\uparrow$}

\author{
Liang Wang, ${ }^{a}$ Jian Zhang, ${ }^{a}$ Xuefeng Wang, ${ }^{\text {bg }}$ Bingsen Zhang, ${ }^{d}$ Weijie Ji, ${ }^{\text {e }}$ \\ Xiangju Meng, ${ }^{a}$ Jixue Li, ${ }^{f}$ Dang Sheng Su, ${ }^{* c d}$ Xinhe Bao*b and Feng-Shou Xiao*a
}

Hydroxyl-attached Sn species are highly dispersed on the surface of mesoporous silica (SBA-15) by the grafting of dimethyldichlorostannane followed by calcination to transform the methyl groups into hydroxyl groups ( $\mathrm{S}-\mathrm{Sn}-\mathrm{OH})$. $\mathrm{S}-\mathrm{Sn}-\mathrm{OH}$ has both Lewis and Brønsted acidic sites, resulting in superior catalytic activities in the acetalisation of glycerol.

Brønsted acid catalysts are of great significance in chemical research and industrial processes. ${ }^{1-3}$ Notably, homogeneous Brønsted acid catalysts such as $\mathrm{H}_{2} \mathrm{SO}_{4}$ and $\mathrm{HCl}$ are widely used, ${ }^{3}$ but they are difficult to separate and regenerate from the reaction systems, making these processes costly and environmentally unfriendly. Compared with homogeneous Brønsted acid catalysts, heterogeneous systems are preferred because of their inherent advantages of easy separation and recyclability. ${ }^{4-6}$ However, the synthesis of highly active and stable heterogeneous Brønsted acid catalysts is still a challenge.

Currently, the introduction of metal atoms into the solid supports is regarded as a typical method to generate heterogeneous acids. One of the most well-known cases is the introduction of $\mathrm{Al}$ atoms into silica, producing Brønsted acid sites. ${ }^{6,7}$ For example, microporous aluminosilicate zeolites, which

${ }^{a}$ Key Lab of Applied Chemistry of Zhejiang Province, Zhejiang University, Hangzhou 310028, China. E-mail: fsxiao@zju.edu.cn

${ }^{b}$ State Key Laboratory for Catalysis, Dalian Institute of Chemical Physics, Chinese Academy of Science, Dalian 116023, China.E-mail: xhbao@dicp.ac.cn

${ }^{c}$ Department of Inorganic Chemistry, Fritz Haber Institute of the Max Planck Society, Berlin 14195, Germany. E-mail: dangsheng@fhi-berlin.mpg.de

${ }^{d}$ Shenyang National Laboratory of Materials Science Institute of Metal Research, Chinese Academy of Science, Shenyang 110016, China

${ }^{e}$ Key Laboratory of Mesoscopic Chemistry, MOE, Department of Chemistry, Nanjing University, Nanjing 210093, China

${ }^{f}$ Department of Materials Science and Engineering, Zhejiang University, Hangzhou 310028, China

${ }^{g}$ School of Environment and Chemical Engeering, Dalian University, Dalian 116622, China

† Electronic supplementary information (ESI) available. See DOI: $10.1039 / \mathrm{c} 3 \mathrm{ta} 14982 \mathrm{j}$ contain highly dispersed $\mathrm{Al}$ atoms in the silica framework, are typical Brønsted acid catalysts and have been widely used in many industrial processes. However, the small pores of zeolites strongly limit their use in the conversion of bulky molecules. ${ }^{6}$ Therefore, great efforts have been devoted to synthesizing mesoporous aluminosilicates, ${ }^{7}$ but their weak acidity severely hinders their wide application due to the amorphous nature of the mesoporous walls. This phenomenon is due to the fact that the Brønsted acid sites of aluminosilicate originate from the protons which are present to neutralize the negative charges of the aluminosilicate walls (Scheme S1a $\dagger$ ). Besides Al atoms, introducing $\mathrm{Sn}$ atoms into mesoporous silica would also generate efficient solid acids, but their acidic sites are only Lewis type (Scheme $\mathrm{S} 1 \mathrm{~b} \dagger$ ), which cannot catalyze reactions requiring Brønsted acid sites. ${ }^{8}$ Therefore, it is a challenge to develop alternative Sn-based catalysts with Brønsted acid sites.

In this work, we propose a simple strategy to create Brønsted acid site on Sn-decorated mesoporous materials. By calcination of dimethyl-modified $\mathrm{Sn}$ on the surface of SBA-15 mesoporous silica (S-Sn-Me), a hydroxyl-attached Sn species ( $\mathrm{S}-\mathrm{Sn}-\mathrm{OH})$ is created (Fig. 1a), which has Brønsted acid properties. Very interestingly, catalytic tests in a model reaction of biomass conversion, i.e., acetalisation of glycerol with acetone to form solketal (2,2-dimethyl-1,3-dioxolane-4-methanol) show that the $\mathrm{S}-\mathrm{Sn}-\mathrm{OH}$ catalyst is very active, compared with conventional Sn-based catalysts.

The S-Sn-OH sample with a $\mathrm{Si}: \mathrm{Sn}$ molar ratio of 66 was synthesized by the grafting of dimethyldichlorostannane onto SBA-15, followed by calcination at $600{ }^{\circ} \mathrm{C}$ for $3 \mathrm{~h}$. Fig. S1A $\dagger$ shows the small-angle XRD patterns of the SBA-15, S-Sn-Me, and $\mathrm{S}-\mathrm{Sn}-\mathrm{OH}$ samples. In the region $0.6-2^{\circ}$, all three samples show three well-resolved peaks that could be indexed to the (110), (200), and (211) reflections of hexagonal mesoporous arrays (Fig. S1A $\dagger$ ), indicating that the hexagonal mesostructure remains stable during the synthesis of $\mathrm{S}-\mathrm{Sn}-\mathrm{OH} .{ }^{9}$ The nitrogen sorption isotherms of S-Sn-OH exhibit a typical type-IV curve, with a hysteresis loop at relative pressure of 0.54-0.79 (Fig. S1B $\dagger$ ), indicating the typical mesoporous structure of 
(a)
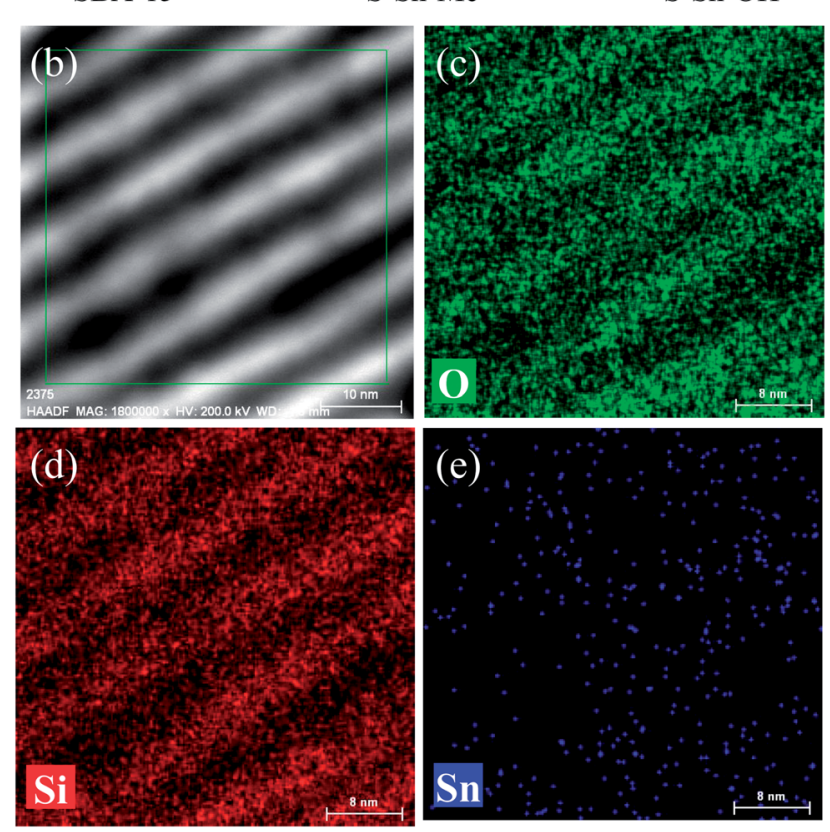

Fig. 1 (a) Scheme for the synthesis of $\mathrm{S}-\mathrm{Sn}-\mathrm{OH}$; (b) STEM image, and (c) $\mathrm{O}$, (d) $\mathrm{Si}$, and (e) $\mathrm{Sn}$ EDS elemental maps of $\mathrm{S}-\mathrm{Sn}-\mathrm{OH}$. The scale bars in the images are $10,8,8$, and $8 \mathrm{~nm}$, respectively.

$\mathrm{S}-\mathrm{Sn}-\mathrm{OH}^{10}$ which could also be directly observed from the TEM images (Fig. S2 $\dagger$ ). The S-Sn-Me and S-Sn-OH samples have relatively low surface areas of $635-677 \mathrm{~m}^{2} \mathrm{~g}^{-1}$ and a pore size distribution of $7.5 \mathrm{~nm}$ compared with the as-synthesized SBA-15 $\left(930 \mathrm{~m}^{2} \mathrm{~g}^{-1}\right.$ and $8.2 \mathrm{~nm}$, Table S1 $\dagger$ ). This phenomenon might be due to the presence of Sn species in the mesopores of SBA-15. ${ }^{11}$

Fig. S3 $\uparrow$ presents the energy dispersive X-ray (EDX) analyses of S-Sn-OH, which show obvious signals associated with Sn species. It is also worth noting that the $\mathrm{Si}: \mathrm{Sn}$ ratios are very similar in the randomly selected areas in $\mathrm{S}-\mathrm{Sn}-\mathrm{OH}$. Interestingly, peaks associated with metallic $\mathrm{Sn}$ or $\mathrm{SnO}_{2}$ crystals were undetectable in the wide angle XRD pattern of S-Sn-OH (Fig. S4†), and Sn species could not be directly observed even in the high-resolution STEM images (Fig. 1b and S5a †). These results suggest the extremely high dispersion of Sn species on the surface of mesoporous silica. Furthermore, we performed elemental mapping analysis of S-Sn-OH (Fig. 1b-e and S5†), from which highly dispersed $\mathrm{Sn}$ was directly observed in different areas of S-Sn-OH (Fig. 1e and S5d $\dagger$ ).

Fig. 2A shows the Sn 3d XPS spectra of S-Sn-Me and S-Sn$\mathrm{OH}$, with the $\mathrm{Sn} 3 \mathrm{~d}_{5 / 2}$ peak at $487.7 \mathrm{eV}$, which is obviously higher than that of the $\mathrm{SnO}_{2}$ crystals $(485.8 \mathrm{eV})$. This phenomenon can reasonably be attributed to the high dispersion of $\mathrm{Sn}$ species. ${ }^{12}$ Fig. 2B shows UV-visible spectra of the various Sn-based samples. The conventional Sn-SBA-15 shows a band at $220 \mathrm{~nm}$, associated with typical $\mathrm{Sn}(\mathrm{OSi})_{4}$ species (Fig. 2B-c). However, S-Sn-Me and S-Sn-OH show bands at 250-255 nm
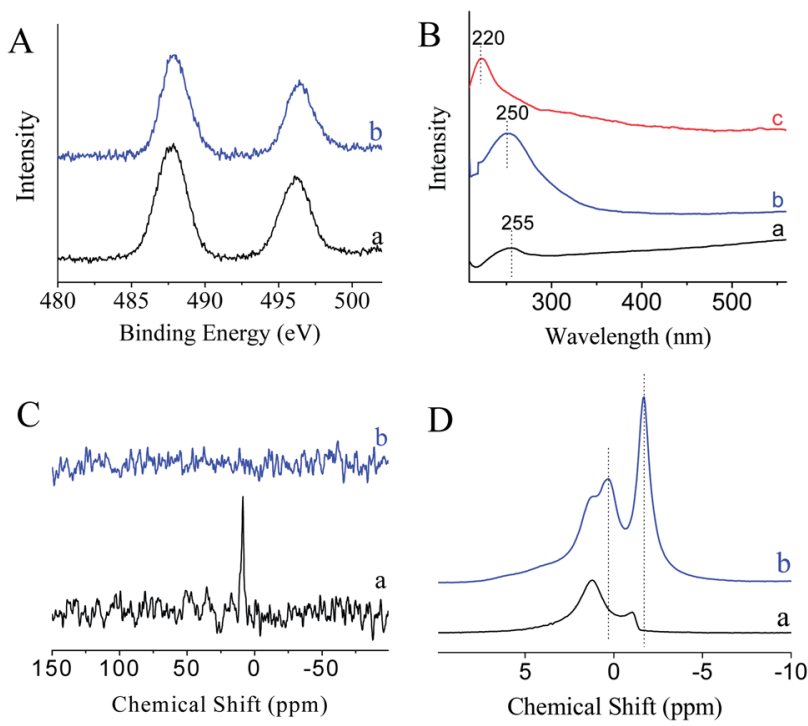

Fig. 2 (A) Sn 3d XPS, (B) UV-visible, (C) ${ }^{13} \mathrm{C} N M R$, and (D) ${ }^{1} \mathrm{H} N M R$ spectra of (a) S-Sn-Me, (b) S-Sn-OH, and (c) Sn-SBA-15.

(Fig. 2B-a and b). This phenomenon might be due to the presence of $-\mathrm{Me}$ or $-\mathrm{OH}$ groups on the Sn species, leading to a change in the electron charge transfer for Sn species. ${ }^{13}$ Fig. 2C shows ${ }^{13} \mathrm{C}$ spectra of $\mathrm{S}-\mathrm{Sn}-\mathrm{Me}$ and $\mathrm{S}-\mathrm{Sn}-\mathrm{OH}$. As we expected, $\mathrm{S}-\mathrm{Sn}-\mathrm{Me}$ exhibits an obvious signal at $8.3 \mathrm{ppm}$, which could be assigned to -Me groups attached to Sn species (Fig. 2C-a). In contrast, the signal at $8.3 \mathrm{ppm}$ is absent in the spectrum of $\mathrm{S}-\mathrm{Sn}-\mathrm{OH}$ (Fig. 2C-b), indicating the dispersion of the -Me groups after the calcination. Fig. 2D shows ${ }^{1} \mathrm{H}$ NMR spectra of $\mathrm{S}-\mathrm{Sn}-\mathrm{Me}$ and S-Sn-OH. Compared with S-Sn-Me, S-Sn-OH shows additional signals at 0.3 and $-1.7 \mathrm{ppm}$, which could reasonably be assigned to the contribution from $\mathrm{Sn}-\mathrm{OH}$ groups, because the only difference between $\mathrm{S}-\mathrm{Sn}-\mathrm{Me}$ and $\mathrm{S}-\mathrm{Sn}-\mathrm{OH}$ is the transformation of the -Me groups on the Sn species to -OH groups.

Fig. 3 shows the IR spectra of pyridine adsorption on the $\mathrm{S}-\mathrm{Sn}-\mathrm{Me}$ and S-Sn-OH samples. The bands at 1454 and $1615 \mathrm{~cm}^{-1}$, which are assigned to coordinatively bound pyridine

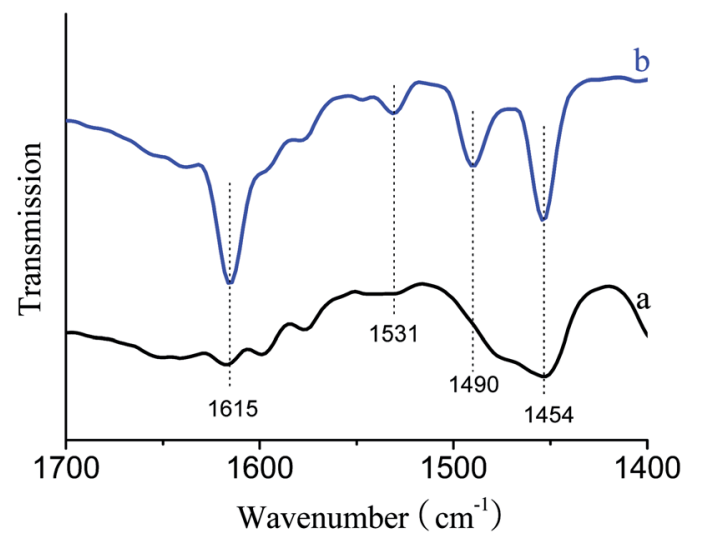

Fig. 3 Pyridine adsorption IR spectra of (a) S-Sn-Me and (b) S-Sn-OH. 
on Lewis acid sites, ${ }^{\mathbf{1 4}}$ exist in both $\mathrm{S}-\mathrm{Sn}-\mathrm{Me}$ and $\mathrm{S}-\mathrm{Sn}-\mathrm{OH}$. Compared with $\mathrm{S}-\mathrm{Sn}-\mathrm{Me}$, the spectrum of $\mathrm{S}-\mathrm{Sn}-\mathrm{OH}$ shows an additional band at $1531 \mathrm{~cm}^{-1}$, which is characteristic of pyridine adsorbed on Brønsted acid sites. ${ }^{\mathbf{1 4 a , 1 5}}$ These results indicate that $\mathrm{S}-\mathrm{Sn}-\mathrm{Me}$ contains only Lewis acid sites, while $\mathrm{S}-\mathrm{Sn}-\mathrm{OH}$ has both Lewis and Brønsted acid sites. Notably, the acidity of S-Sn$\mathrm{OH}$ is strongly dependent on the synthesis conditions. For example, increasing the $\mathrm{Sn}$ content by changing the $\mathrm{Si}$ : Sn ratio from 66 to 35, results in the formation of a Sn-based sample (S-Sn-C1). In the pyridine adsorption IR spectrum, the S-Sn-C1 sample shows three bands at 1453, 1490, and $1613 \mathrm{~cm}^{-1}$, associated with characteristic vibrations of of pyridine adsorbed on Lewis acids (Fig. S6a and Table S1 $\uparrow$ ). Fig. S7† shows the XRD pattern of S-Sn-C1, with obvious peaks at 34.1 and $51.9^{\circ}$, associated with the (101) and (210) planes of $\mathrm{SnO}_{2}$ crystals. Fig. S8 $\uparrow$ shows the STEM image and Sn EDS elemental map of S-Sn-C1, which provide direct observation of the $\mathrm{SnO}_{2}$ crystals. These results suggest that the aggregation of highly dispersed Sn species (e.g. S-Sn-OH) into bulk $\mathrm{SnO}_{2}$ crystals (e.g. S-Sn-C1) would lead to the dispersion of Brønsted acid sites, which might be due to the loss of most of the $\mathrm{Sn}-\mathrm{OH}$ groups on the bulk $\mathrm{SnO}_{2}$ crystals. Additionally, when the S-Sn-Me sample was calcined at $800{ }^{\circ} \mathrm{C}$ (S-Sn-C2), no bands associated with adsorbed pyridine were observed in the pyridine adsorption IR spectrum (Fig. S6b †). The Si : Sn ratio in S-Sn-C2 was established to be higher than 200 (Table S1 $\dagger$ ), indicating the loss of Sn species during the calcination at $800{ }^{\circ} \mathrm{C}$. This phenomenon might be due to the fact that the SBA-15 support and the highly dispersed Sn species are unstable at relatively high temperatures $\left(800^{\circ} \mathrm{C}\right)$.

Glycerol, a major by-product in the production of biodiesel, is produced in large amounts every year. Recently, the conversion of glycerol to more valuable products has been a hot topic. Here, the acetalisation of glycerol with acetone (Fig. 4A) was employed as a model reaction because of the high value of the solketal product. ${ }^{16}$ Both Lewis and Brønsted acid sites are active for the acetalisation of glycerol with acetone, but the Brønsted acids are reported to be more active than Lewis ones. ${ }^{17}$ Fig. $4 \mathrm{~B}$ shows the catalytic data over various acid catalysts; solketal selectivity is higher than $98 \%$ in most cases. S-Sn-Me and conventional SnSBA-15 catalysts, which are typical Lewis acids, ${ }^{18}$ show glycerol conversions of 26.9 and $42.2 \%$, respectively. Interestingly, S-Sn$\mathrm{OH}$, with both Lewis and Brønsted acid sites, exhibits a glycerol conversion as high as $84.1 \%$, which is very similar to that $(83.0 \%)$ of the homogeneous $\mathrm{H}_{2} \mathrm{SO}_{4}$ catalyst. Notably, $\mathrm{S}-\mathrm{Sn}-\mathrm{OH}$ gives a productivity of solketal of $663.7 \mathrm{~mol} \mathrm{~h}^{-1} \mathrm{~mol}_{\mathrm{Sn}}{ }^{-1}$ (Fig. S9†), which is much higher than those over Sn-SBA-15 (249.0 $\left.\mathrm{mol} \mathrm{h}^{-1} \mathrm{~mol}_{\mathrm{Sn}}{ }^{-1}\right), \mathrm{S}-\mathrm{Sn}-\mathrm{Me}\left(213.0 \mathrm{~mol} \mathrm{~h}^{-1} \mathrm{~mol}_{\mathrm{Sn}}{ }^{-1}\right)$, and Al-SBA-15 (59.0 $\left.\mathrm{mol} \mathrm{h}^{-1} \mathrm{~mol}_{\mathrm{Al}}{ }^{-1}\right)$. These results indicate the superior catalytic activity of $\mathrm{S}-\mathrm{Sn}-\mathrm{OH}$ in the acetalisation of glycerol. Considering that the difference between S-Sn-Me and $\mathrm{S}-\mathrm{Sn}-\mathrm{OH}$ is only the presence of Brønsted acid sites, the higher activity of S-Sn-OH than that of S-Sn-Me should be attributed to the contribution of Brønsted acids. The H-ZSM-5, H-USY, and Al-SBA-15 catalysts, which are reported acid catalysts with both Lewis and Brønsted sites, ${ }^{19}$ exhibit glycerol conversions of 24.0, $39.2 \%$, and $65.0 \%$, respectively. These results are all lower than that of S-Sn-OH (84.1\%), which might be because that the small
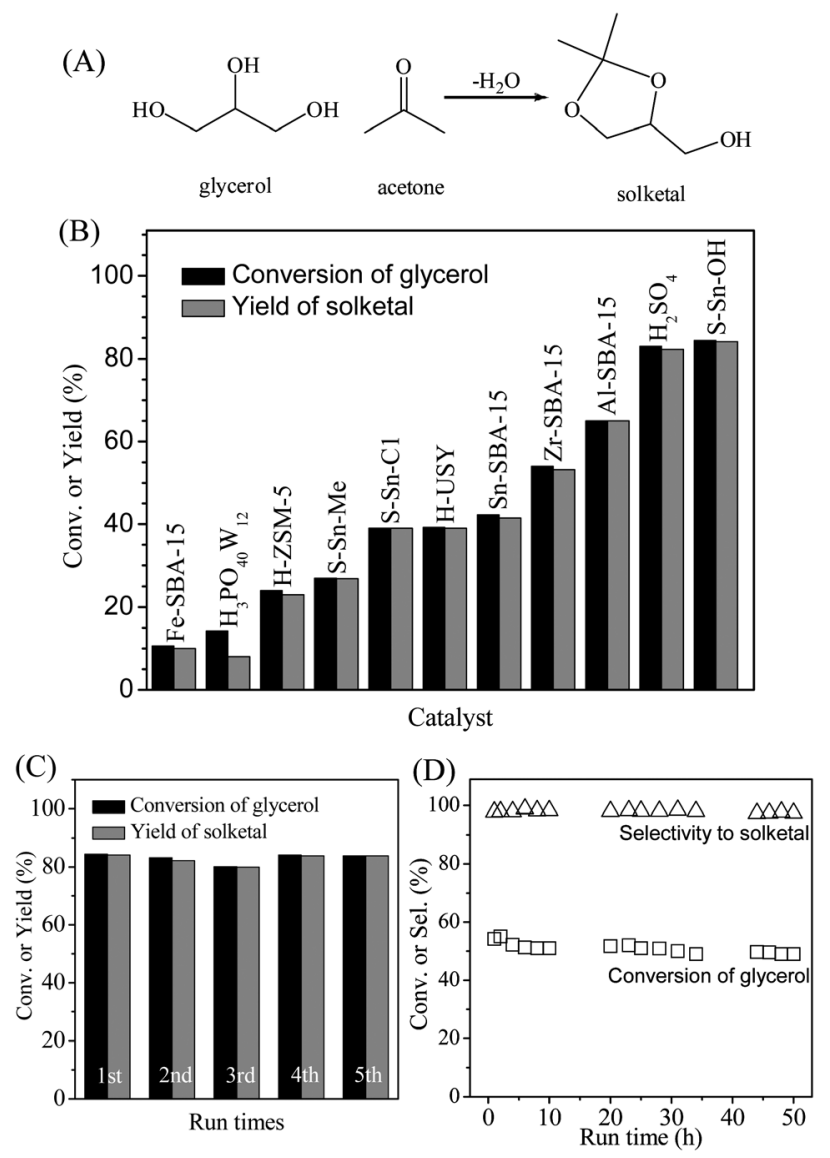

Fig. 4 (A) Scheme for the acetalisation of glycerol with acetone to produce solketal; (B) catalytic data over various catalysts. Reaction conditions: $10 \mathrm{mmol}$ of glycerol, $10 \mathrm{mmol}$ of acetone, $4 \mathrm{~g}$ of $t-\mathrm{BuOH}$, and $50 \mathrm{mg}$ of solid catalyst or $6 \mathrm{mg}$ of $\mathrm{H}_{2} \mathrm{SO}_{4}$, with the temperature of the oil bath at $80{ }^{\circ} \mathrm{C}$ for $6 \mathrm{~h}$; (C) recycling test of $\mathrm{S}-\mathrm{Sn}-\mathrm{Me}$ : the sample was treated in air at $400{ }^{\circ} \mathrm{C}$ for $2 \mathrm{~h}$ after the $3^{\text {rd }}$ use; (D) the acetalisation of glycerol over $\mathrm{S}-\mathrm{Sn}-\mathrm{Me}$ in a fixed-bed reactor. Reaction conditions: $0.1 \mathrm{~g}$ of $\mathrm{S}-\mathrm{Sn}-\mathrm{OH}$ catalyst, glycerol and acetone in $t-\mathrm{BuOH}$ solution $(16.7 \mathrm{wt} \%$

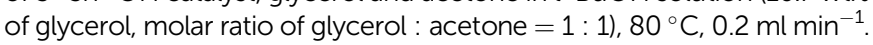

pore size of H-ZSM-5 does not permit the acetalisation to occur inside the pores; H-USY is an aluminium-rich zeolite with a hydrophilic surface, which could keep the formed water inside the pores, weakening the acid sites and inhibiting the acetalisation; the Al-SBA-15 catalyst has $\mathrm{Al}$ species in the amorphous silica walls, leading to weak acidity. ${ }^{\mathbf{1 7 b}, \boldsymbol{c}}$

Fig. 4C shows the recyclability test of the S-Sn-OH catalyst. Even after 4 cycles, S-Sn-OH still gives a high conversion of glycerol of $83.8 \%$. Additionally, after separating the solid catalyst from the reaction system, Sn content in the liquor was undetectable, suggesting there is essentially no leaching of the $\mathrm{S}-\mathrm{Sn}-\mathrm{OH}$ catalyst. More importantly, we tested the catalytic life of $\mathrm{S}-\mathrm{Sn}-\mathrm{OH}$ in a continuous reaction system with a low conversion of glycerol. As shown in Fig. 4D, the glycerol conversion and solketal yield show no obvious decrease in glycerol conversion (49.0-55.2\%) and solketal selectivity (97.4$99.0 \%$ ) over a reaction period of $50 \mathrm{~h}$. These results indicate the high stability and good recyclability of S-Sn-OH for the acetalisation of glycerol with acetone, which offers a good opportunity 
for potentially wide applications of the S-Sn-OH catalyst in the future.

The Sn catalysts were also used to catalyze the conversion of fructose in ethanol (Scheme S2 and Table S2 $\dagger$ ), which could produce different products depending on the nature of the catalyst acidity. ${ }^{3 a, b, 19 a, 20 a}$ For example, ethyl lactate would be formed as major product over Lewis catalysts (Route 1 in Scheme $\mathrm{S} 2 \dagger){ }^{20}$ while HMF could be formed as the major product over Brønsted acids or Brønsted and Lewis acids. Further conversion of HMF leads to the formation of ethoxymethylfurfural and ethyl levulinate (Route 2 in Scheme S2 $\dagger$ ). ${ }^{20,21}$ Sn-SBA-15, S-Sn-Me, and S-Sn-OH catalysts give high fructose conversion (82.3-100\%), but their product selectivities are quite different. Sn-SBA-15 and S-Sn-Me catalysts with Lewis acid sites generate ethyl lactate as the major product (23.9 and 10.2\%). However, S-Sn-OH, with both Lewis and Brønsted acid sites, generates major products of ethyl levulinate and ethoxymethylfurfural. These results are explained by the fact that the presence of Brønsted acid sites on $\mathrm{S}-\mathrm{Sn}-\mathrm{OH}$ can effectively catalyze the conversion of fructose through Route 2 .

In summary, an alternative Sn catalyst with Brønsted acid sites (S-Sn-OH) was created by grafting hydroxyl-attached $\mathrm{Sn}$ species onto the surface of SBA-15. The S-Sn-OH catalyst with Brønsted acid sites shows outstanding performance in the acetalisation of glycerol, a valuable reaction for the utilization of biomass. The results reported here are highly significant since Brønsted acids play important roles in the fields of fuels and energy. The strategy reported in this work will allow the development of more novel Brønsted acid catalysts in the future, which is currently under investigation.

This work was supported by the National Natural Science Foundation of China (21333009, 21273197, U1162201, 21203215), the National High-Tech Research and Development program of China (2013AA065301), the Fundamental Research Funds for the Central Universities (2013XZZX001), financial support provided by the IMR SYNL-T.S. Ke Research Fellowship, and the China Postdoctoral Science Foundation (2012M520652). We thank Prof. L. J. Song and Prof. H. C. Guo for help in IR characterizations.

\section{Notes and references}

1 (a) P. Barbaro and F. Liguori, Chem. Rev., 2009, 109, 515; (b) A. Corma, Chem. Rev., 1995, 95, 559.

2 (a) M. E. Davis, Nature, 2002, 417, 813; (b) C. W. Jones, K. Tsuji and M. E. Davis, Nature, 1998, 393, 52; (c) T. K. Cheung and B. C. Gates, J. Catal., 1997, 168, 522; (d) W. F. Yan, E. W. Hagaman and S. Dai, Chem. Mater., 2004, 16, 5182; (e) J. A. Melero, G. D. Stucky, R. van Grieken and G. Morales, J. Mater. Chem., 2002, 12, 1664.

3 (a) Y. Roman-Leshkov, J. N. Chheda and J. A. Dumesic, Science, 2006, 312, 1933; (b) J. B. Binder and R. T. Raines, J. Am. Chem. Soc., 2009, 131, 1979; (c) G. Yong, Y. Zhang and J. Y. Ying, Angew. Chem., Int. Ed., 2008, 47, 9345.

4 (a) A. Corma and H. Garcia, Chem. Rev., 2003, 103, 4307; (b) M. Hara, T. Yoshida, A. Takagaki, T. Takada, J. N. Kondo, S. Hayashi and K. Domen, Angew. Chem., Int. Ed., 2004, 43, 2955.
5 (a) R. Rinaldi, R. Palkovits and F. Schuth, Angew. Chem., Int. Ed., 2008, 47, 8047; (b) Y. Wang, F. Wang, Q. Song, Q. Xin, S. Xu and J. Xu, J. Am. Chem. Soc., 2013, 135, 1506; (c) Y. Lee, M. B. Park, P. S. Kim, A. Vicente, C. Fernandez, I.-S. Nam and S. B. Hong, ACS Catal., 2013, 3, 617.

6 (a) T. Yokoi, M. Yoshioka, H. Imai and T. Tatsumi, Angew. Chem., Int. Ed., 2009, 48, 9884; (b) F.-S. Xiao, L. F. Wang, C. Y. Yin, K. F. Lin, Y. Di, J. Li, R. Xu, D. S. Su, R. Schlogl, T. Yokoi and T. Tatsumi, Angew. Chem., Int. Ed., 2006, 45, 3090; (c) F. Liu, T. Willhammar, L. Wang, L. Zhu, Q. Sun, X. Meng, W. Carrillo-Cabrera, X. Zou and F.-S. Xiao, J. Am. Chem. Soc., 2012, 134, 4557; (d) X. Y. Yang, G. Tian, L. H. Chen, Y. Li, J. C. Rooke, Y.-X. Wei, Z.-M. Liu, D. Zhao, G. Van Tendeloo and B.-L. Su, Chem.-Eur. J., 2011, 17, 14987; (e) J. C. Kang, K. Cheng, L. Zhang, Q. Zhang, J. Ding, W. Hua, Y. Lou, Q. Zhai and Y. Wang, Angew. Chem., Int. Ed., 2011, 50, 5200; (f) J. Zhou, Z. Hua, Z. Liu, W. Wu, Y. Zhu and J. L. Shi, ACS Catal., 2011, 1, 287; $(g)$ X. Zhang, D. Liu, D. Xu, S. Asahina, K. A. Cychosz, K. V. Agrawal, Y. A. Wahedi, A. Bhan, S. A. Hashimi, O. Terasaki, M. Thommes and M. Tsapatsis, Science, 2012, 29, 1684.

7 (a) Y. Han, F.-S. Xiao, S. Wu, Y. Sun, X. Meng, D. Li, S. Lin, F. Deng and X. Ai, J. Phys. Chem. B, 2001, 105, 7963; (b) C. Li, Y. Q. Wang, Y. Guo, X. Liu, Y. Guo, Z. Zhang, Y. Wang and G. Lu, Chem. Mater., 2007, 19, 173; (c) Z. Zhang, Y. Han, L. Zhu, R. W. Wang, Y. Yu, S. L. Qiu, D. Y. Zhao and F.-S. Xiao, Angew. Chem., Int. Ed., 2001, 40, 1258.

8 (a) E. Nikolla, Y. Román-Leshkov, M. Moliner and M. E. Davis, ACS Catal., 2011, 1, 408; (b) Y. J. Pagan-Torres, T. Wang, J. M. R. Gallo, B. H. Shanks and J. A. Dumesic, ACS Catal., 2012, 2, 930; (c) V. Choudhary, A. B. Pinar, S. L. Sandler, D. G. Vlachos and R. F. Lobo, ACS Catal., 2011, 1, 1724; (d) L. Li, I. Koranyi, B. F. Sels and P. P. Pescarmona, Green Chem., 2012, 14, 1611.

9 (a) D. Zhao, Q. Huo, J. Feng, B. F. Chmelka and G. D. Stucky, J. Am. Chem. Soc., 1998, 120, 6024; (b) L. Wang, X. Meng, B. Wang, W. Chi and F.-S. Xiao, Chem. Commun., 2010, 46, 5003.

10 (a) R. Xu, W. Pang, J. Yu, Q. Huo and J. Chen, Chemistry of Zeolite and Related Porous Materials, Wiley, Singapore, 2007; (b) L. Wang, J. Zhang, S. Yang, Q. Sun, L. Zhu, Q. Wu, H. Zhang, X. Meng and F.-S. Xiao, J. Mater. Chem. A, 2013, 1, 9422.

11 Y. Jin, P. Wang, D. Yin, J. Liu, H. Qiu and N. Yu, Microporous Mesoporous Mater., 2008, 111, 569.

12 (a) A. K. Santra and D. W. Goodman, J. Phys.: Condens. Matter, 2003, 15, R31; (b) G. K. Wertheim and S. B. Dicenzo, Phys. Rev. B: Condens. Matter Mater. Phys., 1988, 37, 844.

13 (a) P. Li, G. Liu, H. Wu, Y. Liu, J. Jiang and P. Wu, J. Phys. Chem. C, 2011, 115, 3663; (b) N. K. Mal, V. Ramaswamy, S. Ganapathy and A. V. Ramaswamy, Appl. Catal., A, 1995, 125, 233; (c) S.-Y. Chen, H.-D. Tsai, W.-T. Chuang, J.-J. Lee, C.-Y. Tang, C.-Y. Lin and S. Cheng, J. Phys. Chem. C, 2009, 113, 15226. 
14 (a) Y. Wang, F. Wang, Q. Song, Q. Xin, S. Xu and J. Xu, J. Am. Chem. Soc., 2013, 135, 1506; (b) N. C. Yang, D. D. H. Yang and C. B. Ross, J. Am. Chem. Soc., 1959, 81, 133.

15 (a) R. Sasikala, A. R. Shirole, V. Sudarsan, V. S. Kamble, C. Sudakar, R. Naik, R. Rao and S. R. Bharadwaj, Appl. Catal., A, 2010, 390, 245; (b) M. Tamura, K. Shimizu and A. Satsuma, Appl. Catal., A, 2012, 433, 135.

16 (a) D. Tilman, J. Hill and C. Lehman, Science, 2006, 314, 1598; (b) U. Biermann, U. Bornscheuer, M. A. R. Meier, J. O. Metzger and H. J. Schafer, Angew. Chem., Int. Ed., 2011, 50, 3854; (c) M. Pagliaro, R. Ciriminna, H. Kimura, M. Rossi and C. D. Pina, Angew. Chem., Int. Ed., 2007, 46, 4434; (d) H. Michel, Angew. Chem., Int. Ed., 2012, 51, 2516; (e) S. Wang, K. H. Yin, Y. C. Zhang and H. C. Liu, ACS Catal., 2013, 3, 2112; (f) J. Zhang, X. Liu, M. Sun, X. Ma and Y. Han, ACS Catal., 2012, 2, 1698; (g) J. Zhang, X. Liu, M. N. Hedhili, Y. H. Zhu and Y. Han, ChemCatChem, 2011, 3, 1294; (h) S. H. Chai, H. P. Wang, Y. Liang and B.-Q. Xu, Green Chem., 2008, 10, 1087.
17 (a) Y. Roman-Leshkov, M. Moliner, J. A. Labinger and M. E. Davis, Angew. Chem., Int. Ed., 2010, 49, 8954; (b) G. Vicente, J. A. Melero, G. Morales, M. Paniagua and E. Martin, Green Chem., 2010, 12, 899; (c) C. X. A. da Silva, V. L. C. Goncalves and C. J. A. Mota, Green Chem., 2009, 11, 38 .

18 (a) P. Shah and V. Ramaswamy, Microporous Mesoporous Mater., 2008, 114, 270; (b) R. Ryoo, S. Jun, J. M. Rim and M. J. Kim, Chem. Commun., 1997, 2225.

19 (a) G. Busca, Chem. Rev., 2007, 107, 5366; (b) W. E. Farneth and R. J. Gorte, Chem. Rev., 1995, 95, 615.

20 (a) Q. Guo, F. Fan, E. A. Pidko, W. N. P. van der Graaff, Z. Feng, C. Li and E. J. M. Hensen, ChemSusChem, 2013, 6, 1352; (b) M. S. Holm, S. Saravanamurugan and E. Taarning, Science, 2010, 328, 602.

21 (a) V. Choudhary, S. H. Mushrif, C. Ho, A. Anderko, V. Nikolakis, N. S. Marinkovic, A. I. Frenkel, S. I. Sandler and D. G. Vlachos, J. Am. Chem. Soc., 2013, 135, 3997; (b) B. Kamm, Angew. Chem., Int. Ed., 2007, 46, 5056. 